\title{
HITZAURREA
}

\section{Xabier Arrazola Iturbe (1962-2015) in memoriam}

DOI: $10.1387 /$ gogoa.15622

Basta un po' di silenzio e ogni cosi si ferma nel suo logo reale, cosí com'è fermo il mio corpo.

(Cesare Pavese, 1933)

GOGOAren 14. Ale hau Xabierri bizi zela eskaini nahi genion, ezintasunak jota erretiroa hartu eta berehala. Kostatako erretiroa, sarritan arnasa hartu ezinik eta ibilera moteldua izan arren, lanerako erabateko ezintasun osoa agintarien sendagile ofizialen batzorde bereziak ez baitzion aitortu hil aurreko hilabete batzuk lehenago baizik. Horrela daude gauzak: hitzetan beti ondo, eguneroko bizitzan maizegi gaizki.

Ondoren datozen testuak laburbilduta aurkezten hasi aurretik, argitaratzaileari dagokiona betez, zilegi bekit hitz laburretan Xabierren oroitzapen pertsonala hemen azaltzea. Filosofia ikasten hasi zen 1983-84 ikasturtean UPV/EHUko Filosofia eta Hezkuntza Zientzien Fakultatean, euskarazko taldean, Donostian. Hurrengo ikasturtean Logikako ikaslea izan nuen eta seguru asko orduan hartu zion gustua gaiari eta kurtsoaren bukaeran pentsatu ere bai bigarren zikloan 'Logika eta Zientziaren Teoria' esaten zitzaion adar bereziari helduko ziola laugarren urtean. Eta halaxe egin zuen 198687an, Logika-II eta Logika-III eta beste ikasgai asko oraindik euskaraz irakasten ez zirenean. Eta erabaki ere erabaki zuten lizentziaturako azken urteko Logika-III ikasgaian matrikulatutako ikasle guztiek (bost ziren) 198788ko klase horiek euskaraz behar zituztela, irakaslea ere euskalduna zenez. Halaxe eman ziren lehen aldiz ereduen teoriaren oinarriak euskaraz, ingelesezko testuen laguntzarekin, eta euskaraz egindako azterketak medio akta gaztelaniaz sinatu beharra izan nuen.

Gasteizko Filologia, Geografia eta Historia Fakultatean euskaraz logika eta zientziaren metodologia irakasteko 'elkartu' plaza bat sortu zen, orduko dekano Patxi Goenagaren eraginez. Xabierrek irabazi zuen hori 1988ko abenduan eta, urte berriarekin batera, Gasteizen hasi zen irakasle. Tesina egin eta, doktorego-programa burututa, tesiari heldu zion, behin Donostiara pasatuta, ekintza kolektibo eta kooperatiboaren gogo-osagai esplikatzaileen logikaz. 
Horrek zabaldu zion bidea Logikako titularitate elebiduna prestatu eta lortzeko, 'Proposizioen Logika, Lehen mailako Predikatuen Logika eta Logika Ez-klasikoak' profilarekin. Gogoan dut epai-mahaiko bost irakasleekin izandako defentsan galdera bati erantzunez hauxe esan zuela bat-batean: «yo, en los cinco años de Filosofía, me he dedicado a estudiar sobre todo lógica y en lo demás a preparar el temario exigido». Epai-mahaikoek, plazaren profila kontuan hartuta, ondo hartu zuten esandakoa, eta mahaiburuari eskatu logikaren aplikazioetan interes filosofikoak sustatzeko titular berriarengan.

Filosofia eta Hezkuntza Zientzien Fakultatea, baldintza zeharo desegokietan, 1978an Zorroagan zabaldu zenetik, ikasketa planak aldaketa etengabean ibili dira Filosofian: lehenik bigarren zikloa mugatuta, gero gerokoak Espainiako Hezkuntza Ministerioaren zorabioaren arabera eta azkenean Bolognako sisteman sartzeko eta, horrekin batera, espazio homogeneo espainolean erroetaraino murgilduz. Xabierrek, ikasle zenetik, sailaren eta fakultatebatzarraren bidez parte oso aktiboa hartu zuen aldaketei buruzko bilkuretan, jakinaren gainean logikarentzat geroz eta bide estuagoa proposatzen zela. Eta gaur gauden bezala gaude: ozta-ozta lortzen dugu filosofia-gradua duen batek lehen mailako predikatuen logikaren oinarriak ezagutzea. Ez du ematen, gainera, gutxi barru egoerak hobera egingo duenik. Azken urteotan Xabierri ez zitzaion erraza izan logikara dedikatzea eta logika irakastea gradu mailan, besteak beste, logikara dedikatu gabeko lotsagabe ezjakin batzuek, sailean bertan, bidea ixten ziotelako ahal zuten heinean. Esana bego. Horrela daude gauzak: urrutitik begiratuta oso ondo, hurretik begiratuta oso gaizki.

Hitz gutxikoa zen Xabier jende artean. Hori bai, esanekoa. Hitza esan eta esandakoa betetzen zuena, kosta ahala kosta. Hitz sakonekoa etxekoen eta lagunen artean. Argi aitor dezadan: ikasle fina, lankide fina, adiskide fina. Egindakoa utzi digu, asko da, eta askotan lan isilaren emaitza, bihotz zabaltasunez egina, neke handiko eta aitorpen txikiko lan isil etengabearen emaitza.

Unibertsitatearen barruan ez zegoen aise. Eta, hala ere, Logika eta Zientziaren Filosofia sailaren sailburu izan zen. Ez zegoen aise. Eta, hala ere, ILCLIren zuzendari izan zen, lehenagotik idazkari izanda, arnasa hartu ezinik geratu arte, unibertsitate publiko espainolaren burokraziaren aurkako eguneroko borrokan indar urritua agortu arte. Jakin bezate guztiek (eta bereziki hainbeste traba jarritako unibertsitate-agintari publikoek) iragarritako heriotzari aurrez aurre begiratu ziola, bizitza modu filosofikoan bizi izan zuelako.

Natorren orain Gogoaren ale honetan bildu diren omenezko testuak aurkeztera. 2015eko apirilaren bukaera aldean hasi ginen lan hau prestatzen eta deia zabaltzean honako izenburu hau jarri genion aleari: Hitza eta Ekintza. Arrazoia eta Emozioa. Proposamenak jasota, testu osoak eskatu, jaso eta ebaluatu ondoren hamaika ekarpen biltzen dira aldizkarian, gehienak hizkuntzaren eta emozioaren eremuetan. 
Lehena Kepa Kortarena da. Hitzaurrean, era hunkigarri batez bere sentimenduak adierazi ondoren (hogeita hamar urte Xabierren ondoan izanda), aurten bertan argitaratu duen testu batean esandakoa zuzentzera dator. Denbora da arazoa «aurresaldiak» egiterakoan, eta lan honetan gertaera kontingenteei buruzko baiezpenak konpromisozko eta zuzentzeko hizketa-ekintzei lotuta esandako batzuk oker daudela azaldu eta aurresaldi guztiek egokitze norabide bera ez dutela argudiatzen du. Eta horrela ondo asko gogorarazten digu lan honek hobe dela norberak bere okerrak zuzentzea eztabaida hutsaletan sartzea baino.

Bigarren ekarpena Mixel Aurnaguerena da. Espazioaren semantikan kokatua dago eta, bereziki, frantsesez mugimenduaz aritzeko moduak ditu aztergai. Kokapen aldaketa, erlazio aldaketa eta bien arteko harremana aztertzen ditu. Mugimenduaren abiadura, norabidea, indar baten aurkako jarduna eta indar batek eragindako mugimendua bilakatzen dira aztergai hizkuntzaren mailan. Amaitzeko Mixel Aurnaguek Jules Supervielleren poema bat eskaintzen dio Xabier zenari, euskarara itzulita.

Mikel Iruskieta, Maria Jesus Aranzabe, Arantza Diaz de Ilarraza eta Mikel Lersundirena da hirugarren ekarpena. Lan honek seigarren ekarpenarekin lotura du, Rhetorical Structure Theory (RSS) erabiltzen baitute biek. Kasu honetan kausazko erlazioak dira aztergai, hizkuntzaren prozesamenduaren eremuan, koherentzia foku berezitzat hartuz. Seigarren ekarpena Jon Alkorta, Koldo Gojenola eta Mikel Iruskietarena da. Eremu berean eta RSS erabiliz, sentimenduen analisia euskarazko testuetan egiteko modua azaltzen da, maila lexikoan. Horretarako beste hizkuntza batzuen azterketan sortu diren teoria eta metodoak konparatzen dira.

Laugarren ekarpena Ibon Coterónena da. Lan honetan hizketa-ekintzen teorian Searlek jarritako oinarria kritikatzeaz gain, Richard Hare filosofo moralaren kontribuzioa seinalatzen da hizketa-ekintzen teoriarako eta, bereziki, kontribuzio horrek izan dezakeen garrantzia euskal aditzaren morfologia eta semantikarako. Adibide batzuk aurkezten ditu lanaren amaieran.

Bosgarren ekarpena Elixabete Perez eta Esther Zulaikarena da. Gazteen arteko txat delakoa da aztergai eta horrelako mezuetan adierazgarritasuna hain zuzen ere. Motiboak ez dira falta komunikazio modu hori alde askotatik aztertzeko eta kasu honetan euskaraz sortzen ari diren adierazpideak eta hizkuntza-baliabideak hartzen dira kontuan, maila lexikoan, fonologikofonetikoan eta morfologikoan, eta baita maila grafikoan ere, adierazgarritasuna ardatz hartuta.

Zazpigarren ekarpena Pello Huizirena da. Gaia honako hauxe: emozioen eginkizuna eta eragina erabakiak hartzerakoan. Askotan errepikatu bada ere azterketa arrazionala dela erabaki zuzenak hartzeko behar-beharrezkoa dena, ez dirudi hori eguneroko praktikan hala denik. Emozioak ekintzaren muinean daude eta erabakiak hartzerakoan hori ahaztea gizakiaren izaera kon- 
tuan ez hartzea litzateke, ondorio larrietan erortzeko arrisku handiarekin. Pello Huiziren lan honetan emozio positiboak eta negatiboak bereizten dira, beti ere erabakiei begira eta halaxe seinalatzen da diziplinarteko hurbilpen teoriko eta praktiko baten premia.

Zortzigarren ekarpena Mikel Haranburu, Nekane Balluerka eta Arantxa Gorostiagarena da. Ditugun emozioak eta izan nahi genituzkeenak bat ez datozenean emozioen erregulatzea beharrezkoa dela esaten zaigu lan honetan, eta erregulatze hori ez dela berez ez on ez txar, ezberdintasuna horren erabilpenaren estrategian dagoelako. Horregatik emozioak erregulatzeko estrategia zabal aztertzen da, kasu psikopatologikoak ere kontuan hartuz. Azkenik, emozioen partekatzea eta kultura-ingurunearen eragina kontsideratzen dira.

Bederatzigarren ekarpena Enetz Ezenarrorena da. Matematikaren filosofian kokatua dago, hain zuzen matematikaren oinarriei buruzko filosofian. Hor filosofia fundamentistak eta ez-fundamentistak deskribatzen eta konparatzen dira. Fregeren eta (gero) Russellen logizismotik hasita, Brouwerren intuizionismora pasatzen da eta Hilberten formalismoarekin bukatzen du proposamen fundamentista tradizionalen zelaia. Lakatosen kuasienpirismoa eta Kitcherren naturalismoa aurkezten dira filosofia ez-fundamentisten alorrean.

Hamargarren ekarpena Javier Aguirrerena da. Aristotelesen Metafisikaren Beta liburuak duen izaera dialektikoa defendatzen du, Topikoetan azaltzen den metodo dialektikoaren arabera. Eta hori gogoan izanda, Beta liburuaren helburua 'lehen' filosofiaren lehen printzipioak aztertzea dela, horiei buruzko ikuspegi ezberdinen egia edo faltsutasuna azalduz. Eta halaxe eztabaidatzen da Betan kontuan hartzen diren premisen nahiz prozedura diaporetikoen izaera, dialektikaren nondik norakoa determinatu ondoren.

Hamaikagarren ekarpena Alain Ulaziarena da. Energetikaren azalpena egiten du hor, sistema konplexu baten moduan, diziplina askoren ikuspegitik aztertu beharrekoa. Lehenik historia labur bat egiten du, ondoren oinarriak markatzen dira Wilhelm Ostwaldek zabaldutako bidetik eta amaitzeko aspektu sozial batzuk azpimarratzen dira, energiari buruzko gogoeta indartzeko asmoz.

GOGOAren eta neure esker ona lan hauen egileei. Esker ona baita ere ebaluatzaileei. GOGOA egileek eta ebaluatzaileek dagite eta, jakina, zuzendariak eta idazkariak. Lan isila. Lan eskerga. Lan aitortu gabea. Sarritan zalantzak sortzen dituena. Ale hau Xabier Arrazola zenaren omenez prestatu dugu. Ez dakit bizi zela prestatu bagenu gogokoa izango zukeen, ezta baimenik emango ligukeen ere. Dakidana da inori ematekotan Kepari eta neuri emango ligukeela.

Donostian 2015eko abenduan

JESUS M. LARRAZABAL 